\title{
O papel do sujeito nos estudos da linguagem
}

\section{Paulo Juarez Rueda Strogenski}

Mestre em Lingüística pela UFPR - Professor de Língua Portuguesa do Cefet-PR - Unidade de Curitiba-paulojrs@cefetpr.br

Resumo:

Os estudos da linguagem sempre apresentaram dicotomias do tipo forma/conteúdo, linguagem/língua, escrita/fala etc. Aqui, pretende-se enfocar uma outra dicotomia: a oposição falante/sujeito. Oposição muito mais filosófica do que formal, através da qual o sujeito é anulado pela maior parte dos estudos da linguagem que prefere se referir àquele que enuncia algo como falante, já que o conceito de "falante" é muito mais facilmente formalizável do que qualquer conceito de "sujeito". O presente trabalho é uma releitura de um ensaio publicado no número 1 desta revista, com o título de Linguagem e Sujeito, através da qual procurar-se-á abordar algumas questões sobre o papel do sujeito,principalmente, na postura teórica de M. Bakhtin.

Desde os primeiros estudos sobre a linguagem, na Grécia Antiga, sempre se procurou dividir aquilo que era visto como linguagem enquanto objeto de estudo - a linguagem literária - e aquilo que, por outro lado, fazia parte do dia a dia das pessoas e por isso era encarado como apenas linguagem cotidiana. A gramática cuidava de estudar o primeiro tipo de linguagem enquanto que o segundo tipo deixava-se para um outro momento (prática, aliás, comum nos estudos lingüísticos).

Outra dicotomia experimentada pelos gregos e legada à tradição dos estudos da linguagem foi a de separar estrutura e expressão: enquanto a estrutura era estudada pela gramática e pela lógica, a expressão era estudada pela retórica; ambos os estudos produzindo fórmulas e "manuais" de como pensar, de como construir e de como expressar para que as palavras "signifiquem" da melhor maneira possível.

A questão do significado e do processo de significação permeia vários campos dos estudos da linguagem desde aquela época. Aristóteles, que pode ser considerado como o criador da Lógica (apesar de que Platão já havia se preocupado com a questão do significado), tentou resumir a estrutura sintática das línguas à fórmula sujeito, verbo de ligação, atributo, de forma que o significado das sentenças poderia ser resolvido silogisticamente. Em "Sócrates é mortal" - o exemplo clássico de silogismo - nós encontramos Sócrates como sujeito, é, verbo de ligação e mortal como atributo. Silogisticamente, a proposição seria interpretada: 1 - Os homens são mortais; 2 - Sócrates é homem; logo, Sócrates é mortal. Casos como "Maria trabalha", que contém um verbo de ação e não um verbo de ligação e nem um atributo, deveriam ser decompostos à forma básica e lidos como "Maria é trabalhadora", transformando-se o verbo trabalha num atributo, trabalhadora, ligado ao sujeito pelo verbo ser.

No entanto, mesmo a forma básica não permitia soluções para todos os casos. Um enunciado 
como Todos os brasileiros são loucos por futebol, apesar de ser constituído por "sujeito" (todos os brasileiros), "verbo de ligação" (são) e "atributo" (loucos por futebol), não pode ser tratada silogisticamente, embora seja uma expressão bem formada, porque o termo "todos" introduz uma noção de totalidade que complica a análise silogística, que consegue dar conta de indivíduos mas não de conjuntos de indivíduos.

A lógica aristotélica sobreviveu como linguagem da "ciência" até o século passado. Atualmente ainda existe, mas mais pelo caráter histórico do que prático. Com o advento das ciências modernas, os cientistas começaram a sentir falta de uma maneira de expressão que não fosse impregnada pela ambigüidade gerada pelas linguagens humanas, porque as linguagens naturais não se prestam ao cálculo e como a lógica aristotélica baseia-se nelas, então seria necessário um modelo lógico capaz de afastar a ambigüidade. Em função dessa necessidade, a partir de trabalhos como o de Frege (Lógica e Filosofia da Linguagem), passou-se a utilizar a linguagem matemática (lógica simbólica), numa tentativa de afastar de vez a influência ambígua da linguagem humana.

De maneira geral, os estudos da linguagem (como os da lógica) sempre se preocuparam mais com a linguagem como um produto acabado, isento das suas condições de produção. $O$ Estruturalismo, inspirado no Curso de Lingüística Geral, de Saussure, nunca considerou o falante como elemento importante na produção lingüística. $O$ objeto de estudo dos estruturalistas sempre foi a língua por ela mesma. A sua intenção era simplesmente a de descrever os diversos sistemas lingüísticos, independentemente das condições de produção ou até mesmo dos falantes que deles faziam uso. Se por um lado essa postura proporcionou à Lingüística o status de ciência formalmente constituída, por outro acabou gerando uma série de equívocos, não só no que se refere ao estudo das línguas, mas também em relação aos métodos de ensino que passaram a ser do tipo "siga o modelo" (prática ainda comum nos dias atuais, quando se dá maior importância à criatividade individual).

O surgimento da Gramática Gerativa-Transformacional (1957), por Chomsky, revolucionou o meio lingüístico porque transferiu a atenção dos estudiosos do objeto pronto (como no Estruturalismo) para o processo essencial de produção. Sem dúvida um passo decisivo para o estudo da linguagem que, a partir daí, começou a se preocupar não só com o resultado empírico do processo lingüístico, mas com os mecanismos biológicos/mentais envolvidos na sua produção. A Lingüística passou, a partir de então, a ser de fato a ciência que estuda a linguagem (no seu sentido mais amplo) e não mais o estudo da língua (produto).

Por outro lado, a Gramática Gerativa, como a concebeu Chomsky, sempre apresentou um grande "inconveniente" para a inclusão do sujeito no processo, que é o conceito de homogeneidade. Para que ela funcione, é preciso antes de mais nada conceber um falante ideal que viva em uma sociedade ideal. Infelizmente (ou felizmente) o nosso mundo não é homogêneo e nós, como seres humanos, menos ainda.

Além desse problema, o de não abranger a falta de homogeneidade do meio lingüístico, a Gramática Gerativa limita-se à sentença complexa e, como se sabe, da mesma forma que as pessoas não se comunicam apenas pela palavra, elas também não se comunicam através de sentenças. Na comunicação humana, é preciso considerar unidades maiores que, apesar de serem formadas por palavras e sentenças, operam pelo estabelecimento de relações 
entre elas. A análise dessas unidades maiores (enunciados, discursos, textos) não pode ficar limitada à morfo-sintaxe porque muito da significação está além desses limites, determinada por fatores extralingüísticos (os dêiticos e os anafóricos são exemplo disso), entre os quais até mesmo o silêncio pode ter significados contextuais.

A necessidade de explicar esses fenômenos extralingüísticos acabou por descortinar um leque de estudos correlatos como os da Sociolingüística e da Psicolingüística. $O$ maior problema dessas áreas é que elas também permaneceram estanques em seus limites, tentando explicar esses fenômenos em função de um tipo de fatores ou de outro, mas nunca a partir de vários tipos de fatores (sociais, psicológicos, ideológicos, históricos, filosóficos, etc.) ao mesmo tempo. Isso ocorre, naturalmente, pelo próprio caráter da ciência, que exige que se parta de um ponto para se chegar a um resultado, seguindo uma determinada linha, ou seja, delimitando o objeto de análise de maneira formal.

Na década de 60 surgiram vários trabalhos que tentaram abordar o estudo da linguagem de maneira mais abrangente na área da Pragmática (entre os quais se destacam os de Oswald Ducrot) e de uma nova linha de pensamento que começou a influenciar os meios lingüísticos e filosóficos: a análise do discurso. Em 1969, Michel Pêcheux lançou a Análise Automática do Discurso, mostrando uma nova maneira de se encarar a linguagem humana ao deslocar o ponto de partida da análise do produto pronto ou do processo interno de produção, segmentado ou não, para as condições de produção, ou seja, o objeto de estudo deixou de estar centrado na fala, na escrita ou no texto em si mesmos para recair nas condições, na situação, no momento de produção, invertendo a linha de raciocínio a respeito do processo de produção. $A$ questão deixou de ser "o discurso existe independentemente do sujeito", como no Estruturalismo ou no Gerativismo, ou "determinado tipo de indivíduo produz determinado tipo de discurso", como na Sociolingüística, para ser "o porquê de determinado tipo de indivíduo produzir determinado tipo de discurso". A atenção passou do texto para o sujeito e para as condições/razões de produção.

Esse sujeito-falante, na concepção de Pêcheux, seria resultado de um processo histórico-social e influenciado ideologicamente, o que o transforma e marca o seu discurso. Se por um lado é facilmente concebível que um sujeito imerso em uma sociedade seja influenciado por ela, por outro, a questão referente à presença de ideologia é bastante discutível.

A análise do discurso nesta linha - chamada comumente de Análise do Discurso Francesa - privilegiou sempre o discurso institucional, o que quer dizer que o trabalho de análise leva sempre em conta a situação discursiva como sendo uma situação-tipo, porque cada instituição, ao possuir características próprias, gera "tipos" de relações, procedimentos, rotinas discursivas, etc. Por exemplo, o discurso médico, o discurso jurídico, o discurso científico, o discurso acadêmico, etc. são, respectivamente, aqueles que ocorrem em situações-tipo da Medicina, do Direito, da ciência, das universidades, etc. Ao se conceber que existam situações típicas, deve-se aceitar também que os sujeitos do discurso fazem parte de um universo típico de cada instituição. Mas se o sujeito é parte desse universo, deve-se propor ou que um sujeito só trafega por um universo e então, também é um sujeito-tipo, um elemento institucional, ou que 
o sujeito (apesar de poder ser participante de uma instituição) trafega por várias instituições e é capaz de assumir cada um dos diversos discursos institucionais.

Os analistas franceses defendem a segunda idéia, a de que o sujeito, ao passar de um ambiente para outro, assume os discursos institucionais possíveis conforme o seu trânsito. $A$ esse processo de adaptação discursiva dá-se o nome de assujeitamento. Esse sujeito assujeitado é então aquele que se apropria de um discurso preexistente e faz uso dele a partir de regras também preexistentes. A conseqüência dessa concepção acaba sendo a de se supor que não existem discursos originais ou textos individuais. A esses discursos não originais dá-se o nome de intertexto. Segundo Eni Orlandi (1988), por exemplo, os textos efetivamente produzidos são intertextos, já que para essa autora a produção discursiva de um falante sempre será atravessada por uma série de discursos preexistentes e mediada ideologicamente. Daí a preferência pelo discurso institucional.

Nessa perspectiva, o sujeito sofre uma redução enquanto participante de uma situação de comunicação: ele sofre o processo de assujeitamento, assumindo não só o vocabulário e as estruturas próprias de uma instituição, mas também as próprias estratégias comunicativas inerentes a ela.

Talvez essa postura teórica se explique porque a partir do momento em que 0 sujeito deixa de ser sujeito e passa a ser assujeitado e o seu texto deixa de ser texto para ser intertexto, o que resta são estruturas já definidas, mais ou menos imutáveis e não criativas, o que vem facilitar o trabalho de análise, já que sempre é mais fácil aplicar-se dados de pesquisa sobre paradigmas do que tentar buscar explicações naquilo que não é "formalizável", naquilo que não é estrutural, mas sim mutável. Um produto do fazer cotidiano daqueles que compartilham uma língua. Isso implica, por outro lado, em uma grande dificuldade para se analisar o discurso fora das instituições, porque é nelas que ele é mais fortemente marcado. Para a análise do discurso francesa, as instituições definidas são o lugar do discurso por excelência. Daí se explica a enorme quantidade de trabalhos específicos sobre os discursos institucionais, como citado anteriormente.

Como se pode perceber, as teorias da linguagem, de maneira geral, não dão maior atenção ao papel individual do sujeito na produção da linguagem. As teorias formalistas geralmente vão tratá-lo como inexistente, ideal ou assujeitado. Em todos os casos, a individualidade do falante acaba sendo excluída.

Nesse universo uma postura que se diferencia é a de M. Bakhtin que se distancia dessas porque consegue colocar o sujeito como elemento participativo e atuante do processo comunicativo. A sua visão histórico-materialista determina ao sujeito uma posição de constante interação com a sociedade e com a linguagem, a qual é vista por ele como um produto social. Como a linguagem é um produto social (e não institucional) e o sujeito é parte atuante do meio social, então ele acaba por também ser um fator de interação.

É muito importante a ênfase que ele procurou dar à linguagem como atividade 
social, pois é a partir daí que surge a argumentação de que o processo de significação é resultado de uma ação social, o que implica em dizer que os signos são mutáveis, já que a sua existência estaria relacionada com um fazer social que não é constante ou imutável, mas sim um processo contínuo do qual toda a sociedade participa.

Apesar de o seu objetivo, em princípio, ser o estudo de aspectos relativos ao discurso na obra literária, as suas reflexões ultrapassam os limites da teoria da literatura e tornam-se reflexões apropriadas aos estudos de uma lingüística abrangente (que ele chama de metalingüística) e não reducionista, diferente da lingüística estruturalista, de inspiração sausseriana, praticada na sua época.

Aliás, é importante lembrarmos que a lingüística que ele conheceu é uma lingüística ainda muito distante das idéias correntes da lingüística textual de hoje, uma lingüística pré-pragmática que ainda estava muito longe de abordagens como as dos atos da fala, de Grice, ou das regras do discurso, de Ducrot. Essas abordagens também não dão conta do discurso, como pretendia Bakhtin, mas estão muito mais próximas do que estava qualquer abordagem estruturalista de sua época. As abordagens estruturalistas, segundo ele, não ultrapassavam o aspecto composicional, ou seja, a forma da linguagem. A análise lingüística, vista assim, seria capaz de perceber os diversos estilos ou até falares, mas não as diversas vozes, justamente o aspecto que interessava a ele: a polifonia, as vozes do discurso.

O seu interesse maior estava nas relações dialógicas existentes entre os discursos, relações estas que são extralingüísticas, não podendo, portanto, ser estudadas pela lingüística, já que "aquela" lingüística tinha como maior interesse as relações de oposição existentes no sistema da língua. Uma língua abstraída do uso concreto da sociedade, o que impedia qualquer possibilidade de análise lingüística do discurso, pois esse "discurso" se faz de uma linguagem inatingível para as análises lingüísticas, linguagem esta que "só vive na comunicação dialógica daqueles que a usam" (Problemas da Poética de Dostoievski, p. 183). Comunicação dialógica que precisa da língua e dos seus aspectos lógicos e semânticos para poder se realizar, mas que jamais poderá ser reduzida apenas a estes aspectos, pois, para realizar-se, precisa ser discurso de um sujeito e superar os limites próprios da língua, ou seja, os limites lógicos e semânticos estudados pela lingüística.

A grande questão que é colocada por Bakhtin é justamente a incapacidade filosófica que a lingüística tradicional, estruturalista e determinística, apresenta para tratar de questões relativas ao discurso, quando o discurso é visto como manifestação de uma interação entre seres humanos, seres dotados de individualidades e intenções que, dificilmente, podem ser abstraídos do contexto real. Ou seja, a língua é um bem social, compartilhado por todos aqueles que fazem parte de uma sociedade, o que faz com que a linguagem seja pluridiscursiva, fruto de "contradições sócio-ideológicas entre presente e passado, entre diferentes épocas do passado, entre diversos grupos sócio-ideológicos, entre correntes, escolas, círculos, etc." (Questões de Literatura e Estética, p. 98) O que implica em afirmar-se que o discurso não pode ser estudado apenas em si mesmo, ignorando-se os fatores externos que o determinam como produto dialógico da sociedade e não como objeto monológico e 
independente que, em última análise, seria um discurso morto.

O discurso deve ser encarado como um diálogo que é produzido em relação a um interlocutor, presente ou não, afinal, "o discurso vivo está imediata e diretamente determinado pelo discurso-resposta futuro: ele é que provoca esta resposta, pressente-a e baseia-se nela" (p.89). Isso porque o falante, ao produzir um discurso, o faz em relação a um ouvinte. Ele cria um conjunto de significações e o estende a outra pessoa, invadindo o círculo perceptivo e contando com a capacidade de compreensão do seu conjunto de significações por outro indivíduo. Ninguém produz discursos para as pedras (pelo menos não normalmente) e mesmo que converse com as pedras, provavelmente o fará atribuindo características anímicas para elas, imaginando quais seriam suas respostas ou questionamentos ou dúvidas, etc., num processo dinâmico, dialogicamente constitutivo do discurso.

Cada sujeito, como parte da sociedade a que pertence, teria então o seu papel enquanto agente modificador na atividade social. Mesmo assumindo que no discurso de um sujeito possam estar presentes outros discursos anteriores, a sua forma de analisar o processo de apropriação do discurso alheio pressupõe um sujeito ativo e atuante, capaz de fazer escolhas e estabelecer estratégias. Aí reside a diferença básica entre a análise do discurso francesa e o pensamento de Bakhtin. Enquanto a primeira admite apenas um sujeito assujeitado, o segundo propõe um sujeito ativo, capaz de utilizar a linguagem para a formação de sua consciência individual e também de usar a sua individualidade para interferir no processo social da linguagem, através da sua atividade interacional constante junto à sociedade.

A concepção bakhtiniana atribui ao sujeito responsabilidade pelo uso que este faz da linguagem. O sujeito não é somente um divulgador de discursos preexistentes, mas sim um agente dentro do processo discursivo, capaz de interferir, aprimorar ou até modificar o discurso social. Esta distinção é possível pelo fato de Bakhtin, ao contrário da análise do discurso francesa, conseguir ver o discurso na sua dimensão social. Dimensão esta que contém também as dimensões institucionais e as ultrapassa, sendo parte expressiva do conjunto de relações da atividade histórico-social.

Em resumo, a posição do sujeito frente à linguagem varia conforme a época ou o interesse. Se por um lado podemos imaginar que os estudos lingüísticos da língua por ela mesma, como os praticados numa perspectiva estruturalista, possam e até devam desprezar o papel comunicativo do sujeito para de fato centrar todo o interesse na estrutura da língua sem interferências (que aí serão subjetivas), por outro, não se pode imaginar que se pratique algum tipo de estudo do discurso sem atribuir um papel relevante ao sujeito.

Acredito que, ao menos em princípio, possamos pensar a questão de duas maneiras um pouco diferentes. Na primeira, podemos supor que exista o primado do discurso (muitos pensam assim), isto é, que o discurso pré-existe aos sujeitos e cada sujeito, ao nascer, já seria uma espécie de refém dos discursos sociais aos quais estaria exposto. Talvez seja assim, mas, já num primeiro momento, surge um paradoxo interessante: se por um lado o sujeito 
é refém de um discurso que o precede, por outro o discurso precisa do sujeito para ser produzido, ou seja, o discurso é refém do sujeito que é refém do discurso. Na segunda, podemos supor, ao contrário, que exista o primado do sujeito, o qual se utilizaria de estruturas lingüísticas (não de discursos) pré-existentes para produzir seus discursos, que até poderiam ser influenciados por discursos de outros, mas que seriam originais.

Talvez até se possa imaginar que na realidade exista uma possibilidade conciliadora e defender que discurso e sujeito sejam realidades interdependentes e igualmente fortes no processo comunicativo. Ou seja, talvez esteja correto o paradoxo proposto no parágrafo anterior: 0 discurso é refém do sujeito que é refém do discurso que é refém do sujeito que é refém do discurso...

Bibliografia citada:

BAKHTIN, Mikhail. Questões de Literatura e Estética. São Paulo: Ed. Hucitec, 1988.

Problemas da Poética de Dostoiévski. $2^{\text {a }}$ ed. Rio: Forense- Universitária, 1997.

Marxismo e Filosofia da Linguagem. São Paulo: Editora Hucitec, 1986.

CHOMSKY, N. Aspectos da Teoria da Sintaxe. Coimbra: Américo Amado Editor, 1978

FREGE, G. Lógica e Filosofia da Linguagem. São Paulo: Cultrix, EDUSP, 1978.

ORLANDI, E.P. Discurso e Leitura. São Paulo: Cortez Editora-Unicamp, 1988.

PÊCHEUX, M. Análise Automática do Discurso, (1969), in GADET, F. \& HAK, T. Por uma Análise Automática do Discurso. Campinas: Unicamp, 1990. 